\title{
Actualidad e inactualidad de Séneca
}

\section{Juliana González}

Paul Veyne, Sénèque, Editions Robert Laffont, París 1993.*

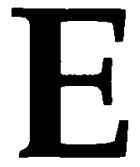

1 Sénèque de Paul Veyne -uno de los autores más autorizados en la cultura latina-constituye un significativo aporte a la hermenéutica contemporánea de este gran clásico de la filosofia moral, particularmente importante para el mundo hispánico.

Se trata de un estudio, tan riguroso como fluido y cristalino, que busca la actualización del clásico latino-cordobés, sustentado, por un lado, en el hondo dominio que el Profesor del Collège de France tiene de las fuentes, primarias y secundarias, y por el otro, en su conocimiento de filósofos contemporáneos y, sobre todo en la percepción de un cierto clima intelectual y moral que priva en el presente.

Y es en razón de destacar la actualidad de Séneca, que el libro de Paul Veyne concede una decisiva importancia a las Cartas a Lucilio, por encima de otras obras del clásico latino, quien, por lo demás, es visto en todo momento dentro del contexto del estoicismo en general (mismo que significativamente, no se interpreta -como suele hacerse- en sus posibles conexiones con algunas concepciones orientales, sino como estricta manifestación de la cultura greco-romana, debido principalmente a su señalado racionalismo).

La actualización de Séneca se alcanza por diversas vías. Primeramente, por algunas aproximaciones y analogías que Veyne percibe entre el estoicismo y la concepción marxista de la historia. Ambos tendrían en común sobre todo la idea de una racionalidad que se cumple indefectiblemente; o sea, el determinismo y el fatalismo de ambas filosofias. Veyne encuentra además importantes similitudes entre las concepciones estoicas y algunas ideas de la teoría económica moderna.

Pero, ante todo, la actualidad de Séneca (y del estoicismo) se halla, para Veyne, en la significación del "yo". Su interpretación se centra aquí en el

* De próxima aparición en el FCE. 
posible paralelo que puede encontrarse con la concepción moderna, y el valor que ésta concede también al "yo" -sin que esto implique soslayar las grandes diferencias que el presente ofrece frente al optimismo y al racionalismo estoicos.

El autor de Sénèque es, desde luego, consciente de las distancias históricas y culturales que hay entre la concepción estoica y la modernidad. Pero al mismo tiempo, encuentra aquellos puntos de coincidencia en donde resulta que, paradójicamente, en el mundo moderno, y sobre todo en el "posmoderno", la conciencia de la pérdida de todo asidero, de toda referencia a algo estable y consistente, ocasiona que, en esta realidad evanescente y "leve" sólo persista la fuerza del "yo", y sobre todo la capacidad que éste puede tener de auto-transformarse, de actuar sobre sí mismo y enfrentar una realidad absurda, sin sentido, haciendo cara incluso a la muerte. Esto es lo que a juicio de Paul Veyne, acerca a Séneca al mundo actual. En este sentido, la obra de Veyne se halla ligada, como él lo dice expresamente, a la reinterpretación que de Séneca intentó hacer Foucault en sus últimos años.

La preocupación central que aproxima el estoicismo en general a nuestro presente es, según Veyne, la idea de que no se trata de fundar una moral sino un "arte de vivir" que permita al hombre encontrar en sí mismo, en su propio "yo", el punto fijo y la fortaleza moral. De este arte de vivir depende la transfiguración que el "yo" pueda ejercer sobre sí mismo reencontrando aquí una esperanza de salvación.

La lectura que Veyne hace de Séneca se realiza, por lo demás, con plena conciencia de que no cualquier interpretación es válida y de que, por mucho que el presente llene de algún modo los pensamientos de la antigüedad, esto no implica que se haga de manera arbitraria y que se pueda leer de cualquier manera el pensamiento del pasado.

Cabe decir, incluso, que la exposición que el autor de Sénèque hace del estoicismo es tan pulcra y objetiva que, al adentramos en las ideas estoicas fundamentales, lo que se hace más palpable es la diferencia, la distancia radical que tales concepciones pueden tener respecto a la visión contemporánea. El racionalismo y la visión naturalista y optimista de la naturaleza; la convicción de que el hombre forma parte de esa perfección natural; el ideal mismo de la apathía, como extirpación de las pasiones; la concepción de que éstas no son intrínsecas a la naturaleza originaria del hombre, sino distorsiones de su naturaleza, la cual es esencialmente racional y de que, por tanto, extirparlas es "vivir conforme con la naturaleza" y así alcanzar la seguridad interna, clave última de la felicidad; la creencia, en suma, de que ésta se cifra en la liberación del hombre de todo lo que le sujete al mundo, y particularmente en la liberación frente al sufrimiento y a la muerte. Todo ello, que constituye el contenido esencial del estoicismo, resulta ciertamen- 
te muy lejano para el presente. En especial lo es -como señala Veyne- la idea estoica de la unidad simple del alma: ésta no tendría para los estoicos ni dualidades ni contradicciones. Y todo sería en la vida humana cuestión de conocimiento, de razonamiento correcto o incorrecto. El sabio estoico no es sino el hombre que sabe razonar y vive en la verdad.

Veyne intenta expresamente no caer en anacronismos proyectando nuestras propias ideas sobre los otros pensamientos. No pierde, en suma, la conciencia de que los tiempos de Séneca son "tiempos lejanos" y que el sabio latino poseía otro mundo mental, con otros horizontes, bien distintos a los nuestros.

Sin embargo, cabe decir también que Veyne alcanza la actualización de Séneca por vía, justamente, de contrastación, de discusión con las ideas estoicas; mediante el análisis crítico que hace permanentemente de esas ideas, tan opuestas a la concepción que hoy puede tenerse de la naturaleza humana. Gran parte del interés y vivacidad que ofrece esta obra se debe precisamente a que ella discurre como un diálogo crítico con Séneca y el estoicismo, en una constante problematización y discusión con los supuestos racionalistas y monistas que los caracterizan.

Como una consecuencia de esa lectura pulcra y original que Veyne realiza de Séneca y el estoicismo se hace posible poner de relieve algunos aspectos del pensamiento de éstos que no han sido suficientemente toma. dos en cuenta, entre los cuales cabe destacar:

a) La idea estoica del esfuerzo ético: del ejercicio constante y cotidiano como fuente necesaria para la creación del hábito virtuoso y, con él, de la autotransformación o autotransfiguración que permite alcanzar la seguridad y la felicidad, como condición necesaria para realizar "esa humanidad que es tan rara entre los hombres".

b) El hecho de que, a pesar de que los estoicos ponen el eje de la vida en el "yo" y su seguridad interior, y no en bienes o males externos, hay sin embargo en el estoicismo los "preferibles"; es decir, contenidos valorativos, y no sólo un racionalismo vacío: la vida, la salud, el bienestar, son preferibles a la muerte, la enfermedad, el sufrimiento. Aun cuando el sabio tiene en sí su principio de bien y mal y puede enfrentar con igual felicidad incluso las torturas y la muerte, no obstante "es preferible" no sufrir la tortura. Paul Veyne destaca aquí lo que él llama ciertas incoherencias o inconsistencias del estoicismo que son justamente las que permiten hacer de éste una lectura más rica.

c) La significación esencial que la muerte y, en consecuencia, el suicidio, tienen para Séneca.

La muerte para el estoico tiene una "omnipresencia inconsciente" -dice Veyne- que atraviesa toda la vida. Se entiende así que el reto supremo 
del sabio sea poder trascender el miedo a la muerte para adquirir la suprema seguridad interior y felicidad (idea que, como también indica Veyne, comparte el estoicismo con los epicúreos). Consecuentemente, como es sabido, el suicidio adquiere para Séneca el significado del "acto supremo de la vida". Lo que cuenta para el sabio es la manera de morir, la entereza, la libertad interior frente a la muerte. En este sentido, el suicidio no se explica, a juicio de Veyne, en términos de "mal del Siglo" o de "tedio Vital", sino como la firme creencia en que en él se encuentra la clave de la libertad.

De ahí el significado excepcional que tiene el propio suicidio de Séneca, a cuyo relato y análisis el libro de Veyne dedica el "epílogo", siguiendo como fuente los Anales de Tácito.

d) La significación de las creencias, las ideas y los ideales del estoicismo que a juicio de Veyne son la clave para la comprensión de éste, y no tanto sus causas históricas, ni sociales, ni sus raíces psicológicas. Veyne sostiene que, en general, (y esto es central en la hermenéutica que realiza de Séneca), las creencias son como una especie de "espíritu objetivo" que "atrapa" a los creyentes, insuflándoles el aliento y el sentido de sus vidas. El estoicismo -añade Veyne- nunca cumplirá su ideal: pues nunca se logra la sabiduría, la liberación total. Sin embargo, basta la creencia: ésta ya es ganancia vital. El budista no alcanza el Nirvana, el taoísta no logra la inmortalidad, el psicoanálisis no cura, pero ayudan a vivir, procuran una pasión y transforman al creyente en su interioridad, dando sentido a su existencia. En el hombre -dice Veyne- el "ser en potencia" tiene "actualidad": la virtualidad vale tanto como las realidades mismas; lo potencial opera en la vida humana como podría operar una realidad.

Por otra parte, Veyne resalta la conciliación estoica entre la búsqueda individualista de la felicidad y el altruismo. Idea que está en íntima consonancia con la religiosidad naturalista y la idea de los estoicos de que cada hombre es en si parte, y al mismo tiempo, el modelo del cosmos: es un microcosmos. Por eso se olvida de las desgracias y puede reencontrarse con los otros hombres.

Para el estoico el hombre es amigo del hombre. La moral viene de la naturaleza (ella siembra en el ser humano la "prenoción" de la justicia) y el mismo instinto que permite coexistir en paz a los animales es el que aproxima a la humanidad entre sí. Prevalece, así, la idea de que la virtud, en la medida en que se realiza, favorece a los otros. Aun cuando la función de la virtud no sea altruista, ella rinde un servicio a los hombres. En este punto Séneca está en la misma situación que Epicteto, para quien "nadie puede buscar su bien particular sin contribuir a la utilidad universal". Séneca a su vez dirá que "si tú no haces nada por otro no harás nada en absoluto".

La naturaleza nos ha creado hermanos. En la medida en que el hombre 
realiza el microcosmos, no cabe el egocentrismo. El respeto al otro es esencial. Por eso obedecer la fatalidad cósmica es entrar en el orden de la racionalidad y aceptar que el destino es la fuente de la serenidad.

Pero esto no significa que la igualdad o la unidad humana entre los estoicos no sea, a juicio de Veyne, una idea abstracta, ni que de ella pueda inferirse que haya una variante realmente esencial entre la concepción estoica de la esclavitud y la aristotélica. (Como tampoco puede anacrónicamente suponerse que la idea del "cosmopolitismo" de los estoicos pueda equivaler al internacionalismo moderno).

La obra de Veyne dedica muchas páginas precisamente al análisis de las diferencias entre la concepción aristotélica de la esclavitud y la estoica, para concluir que ambas desembocan en el mismo statu quo. Pues aun cuando los estoicos no denigran el trabajo manual y acentúan la idea de que la virtud de "humanidad" implica el buen trato a los esclavos, y aun cuando sostienen, en definitiva, que éstos son "humildes amigos", "asalariados a perpetuidad", no se ha alterado en esencia la concepción fundamental de la esclavitud: ésta se conserva bajo otro nombre.

Pero además, Veyne hace hincapié en que la idea de una hermandad natural interhumana y de un altruismo natural tampoco significan que no haya, en particular en Séneca, una conciencia del mal moral y del mal de la historia; hay incluso en el estoico cordobés una "sensibilidad amarga" frente a los males de la historia. En el tiempo de Séneca se estaría viviendo, según éste, la decadencia de un ciclo cósmico que haría patente que los hombres están ya "viejos para la libertad". Las Cartas a Lucilio de Séneca (y en especial la Carta 73) no son, para Veyne, sólo "un texto de oposición" política al neronismo, y de hecho una acusación implícita a Nerón y a toda una sociedad que estaba a juicio de Séneca entera y originalmente perverti$\mathrm{da}$, sino también "una inmensa alusión al error universal".

Pero hay salvación. No por la vía de la política (en la cual los estoicos creen poco), sino por la cura ética de cada uno de los individuos. Se trata de corregir la perversión inicial, y reeducar al hombre para que, al vivir conforme con la naturaleza, se recobre la virtud y la racionalidad.

Veyne insiste en que para los antiguos no hay propiamente problema de la libertad y menos aun en sentido moderno. La libertad es una evidencia intuitiva que se da por hecho y se conjuga, sin cuestionarse, con el Destino o la Fatalidad. El mal es sólo mal moral y éste es humano. La liberación la alcanza el individuo; es él quien la determina, es él el agente libre. La libertad se cifra, así, en la capacidad del hombre de asumir la racionalidad propia y con ella la racionalidad natural, para así alcanzar la felicidad. Esto es lo que significa el apotegma fundamental de los estoicos del "vivir conforme con la Naturaleza". 
La obra de Paul Veyne se completa con rigurosos y valiosos estudios críticos y las correspondientes traducciones de las pequeñas obras de Séneca tales como "De la vida feliz", "La constancia del sabio", "La tranquilidad del alma". Estas obras mantienen ciertamente una importante unidad con el ensayo general de Veyne y lo enriquecen. 